\title{
REASONING ABOUT SOCIAL PHENOMENA
}

The initiative of this Special Issue of the Bulletin of the Section of Logic was born during one of the Chinese-Polish Workshops on Applied Logic and is connected with the developing collaboration between Chinese and Polish logicians. On the one hand, Poland has a long and strong presence in Western logic, which is witnessed by many influential works in the field from the rise of modern logic until today. On the other hand, China has its own logical tradition that can be traced back to ancient times. The study of it is actually a research field in present China. Somehow independently of it, Chinese scholars also make their input to the modern, Western-rooted logic. Among other sources of inspiration, some works of Polish logicians influenced the development of logic in modern China. One example of this is Łukasiewicz's book 'Aristotle's Syllogistic from the Standpoint of Modern Formal Logic', which was published originally in 1951 and was translated to Chinese in 1981 as a part of the well-known series Chinese Translation of World Academic Classics [1]. Another example is Ziembiński's book 'Practical Logic', which was published originally in 1959 and was translated into Chinese in 1988 [2]. This book played an important role in the study of legal logic in China.

The community of Polish logicians is quite active, while the community of Chinese logicians has got bigger in recent years. However, the interaction between the two communities could hardly be observed until quite recent times. The series of Chinese-Polish Workshops on Applied Logic was meant to change this situation. The first event took place at Beijing Normal University in 2017. The second one took place at Nicolaus Copernicus University in Torun in 2018. The third one took place at Zhejiang University in 2019.

(C) Copyright by Author(s), Łódź 2021

(C) Copyright for this edition by Uniwersytet Łódzki, Łódź 2021 
The distinguished topic of the third Workshop was 'Reasoning about social phenomena', which is also the core subject of the present Special Issue. The choice of the topic reflects the shift of the perspective from the point of view of a single, abstract, ideal subject to the more realistic perspective of multiple, imperfect, interacting subjects, that can be observed in recent decades in logic. The workshop gathered, apart from the Chinese and Polish participants, a group of researchers from other Asian and European countries and gave the participants an oportunity to have very interesting discussions. The program is listed on the workshop webpage: www.xixilogic.org/events/3rd-chinese-polish-workshop/

The call for papers for this Special Issue, following the workshop, encouraged contributions on the following subjects: philosophical logic (deontic, epistemic, causal, probabilistic, etc.) within social context; multi agent logics; non-monotonic reasoning (particularly in cognitive science); formal social sciences; formal ethics.

We received nine submissions and after a careful reviewing process, five of them that fulfilled high scientiffic standards and were relevant to the subject. Let us now briefly summarise their motivations and main contributions.

Federico L. G. Faroldi's paper Towards a Logic of Value and Disagreement via Imprecise Measures (pp. 131-149) provides a novel way to formalize how we value things. The solution is based on imprecise measures of values. Then it proposes a logic, called Hyperintensional Value Logic, to make sense of value disagreement among people.

Daniela Glavaničová and Matteo Pascucci's article The Good, the Bad, and the Right: Formal Reductions Among Deontic Concepts (pp. 151-176) provides a logical analysis of two important notions in deontic logic: normative ideality and normative awfulness. Then, it studies how to define obligation, explicit permission and Hohfeldian relations by the two notions.

The paper Tableau Systems for Epistemic Positional Logics by Mateusz Klonowski, Krzysztof Aleksander Krawczyk, and Bożena Pięta (pp. 177204) presents a set of logics for analyzing some important epistemic modalities such as knowing and believing, which are based on positional semantics. Sound and complete tableau systems are provided for these logics.

The article Extended MR with Nesting of Predicate Expressions as a Basic Logic for Social Phenomena by Aleksander Parol, Krzysztof Pietrowicz, and Joanna Szalacha-Jarmużek (pp. 205-227) aims to develop new perspectives on the applications of positional logic to issues of social sciences such 
as sociology. It presents a positional logic which extends the MR logic with new expressions for describing complex social situations.

Richmond H. Thomason's article Common Knowledge, Common Attitudes, and Social Reasoning (pp. 229-247) discusses arguments against the thesis that people can acquire common knowledge and that common attitudes are needed in social reasoning. The author argues that this skepticism is based on implausible assumptions and thinks that there is enough room for common knowledge in social discourse.

This Special Issue completes a chapter of the research activities on logic supporting reasoning about social phenomena. Most of the papers included in it provide clear guidelines for further research. As the editors of the Special Issue, we are commited to continue the common academic activities of logicians from China and Poland. We believe that the activities succesfully support the research in the field, contribute to the development of logic, and serve the international community of logicians. We are interested in extending our research topics to some emerging areas, espacially logic in new generation artificial intelligence.

Acknowledgements. We want to thank all authors for their contributions and the reviewers, who in this difficult pandemic times responded to our requests for comments and in many cases allowed the authors to improve their works. There would not have been this special issue without their contribution. Special thanks go to the participants of Zhejiang University 2019 meeting for providing inspiration, and - last but not leastEditor-in-Chief of BSL, prof. Andrzej Indrzejczak who encouraged us to prepare this Special Issue of the Bulletin of the Section of Logic.

Tomasz Jarmużek Fengkui Ju Piotr Kulicki Beishui Liao 


\section{References}

[1] J. Łukasiewicz, Aristotle's Syllogistic from the Standpoint of Modern Formal Logic, The Commercial Press (1981), translated to Chinese by Zhen $\mathrm{Li}$ and Xiankun Li.

[2] Z. Ziembiński, Practical Logic, Qunzhong Press (1988), translated to Chinese by Shengen Liu.

Tomasz Jarmużek

Nicolaus Copernicus University in Toruń

Chair of Logic

ul. Stanisława Moniuszki 16/20

87-100 Torun, Poland

e-mail: tomasz.jarmuzek@umk.pl

\section{Fengkui Ju}

Beijing Normal University

School of Philosophy

19 Xinjiekouwai Street

100875 Beijing, China

The John Paul II Catholic University of Lublin

Institute of Philosophy

Aleje Racławickie 14

20-950 Lublin, Poland

e-mail: fengkui.ju@bnu.edu.cn

\section{Piotr Kulicki}

The John Paul II Catholic University of Lublin

Institute of Philosophy

Aleje Racławickie 14

20-950 Lublin, Poland

e-mail: piotr.kulicki@kul.pl 


\section{Beishui Liao}

Zhejiang University

Institute of Logic and Cognition

148 Tianmushan Road

310058 Hangzhou, China

e-mail: baiseliao@zju.edu.cn 